\title{
Ensinando Conteúdos Matemáticos Usando Anamorfose
}

\author{
Claudio Iavorski*, Olga Harumi Saito, \\ Mestrado Profissional em Matemática em Rede Nacional - PROFMAT, \\ Departamento Acadêmico de Matemática, UTFPR, \\ 80230-901, Curitiba, PR \\ E-mail: claudio-iavorski@hotmail.com, harumi@utfpr.edu.br,
}

\begin{abstract}
Resumo: A anamorfose consiste, basicamente, em deformar uma imagem no plano, de modo que ela só possa ser vista como era originalmente de um ponto de vista único e/ou por um sólido geométrico refletor único. É uma mistura de matemática, perspectiva e arte. O seu uso no ensino de Matemática possibilita o desenvolvimento da percepção, por parte dos alunos, usando conhecimentos como a trigonometria e coordenadas cilíndricas, motivando-os para o uso destes conhecimentos vinculados a arte. Esta "Matemática do Disfarce" permite usar o conhecimento matemático como ferramenta para impressionar, gerar ilusões de ótica e interagir com o observador por meio da arte.
\end{abstract}

Palavras-chave: Anamorfose, perspectiva, óptica, interdisciplinaridade, AnamorphMe.

\section{Introdução}

Anamorfose, do latim anamòrfosis (reiteração da forma), é uma técnica que foi muito usada na pintura de murais dos séculos XV e XVI. Era feita principalmente para gerar efeitos de profundidade e dupla interpretação de imagens. Acredita-se que teve origem na China antiga, porém não existem registros que comprovem isso. Pelo fato de ter uma grande fundamentação matemática e física, pode ser usada em diversos conteúdos desde o ensino fundamental até o ensino médio. Pode assumir papel de ferramenta motivadora, usada na montagem de atividades ou como ponte de ligação entre a matemática, física e artes visuais.

Quando se reflete uma imagem em um cilindro espelhado, por exemplo, tem-se uma imagem deformada, porém essa deformação segue alguns padrões. Ao construir uma anamorfose deve-se, com o uso da matemática, identificar esses padrões de modo que se construa uma imagem plana deformada que refletida no cilindro, volta a sua forma original.

O processo envolvido na técnica de criar uma figura anamórfica ficou por muito tempo no esquecimento, sendo resgatada no século passado. Um dos destaques nesta arte é o húngaro István Orosz, com uma riqueza de detalhe em seus trabalhos que aguçam a curiosidade de todos, Figura 1.

${ }^{*}$ Bolsista de Mestrado Profmat (Capes) 


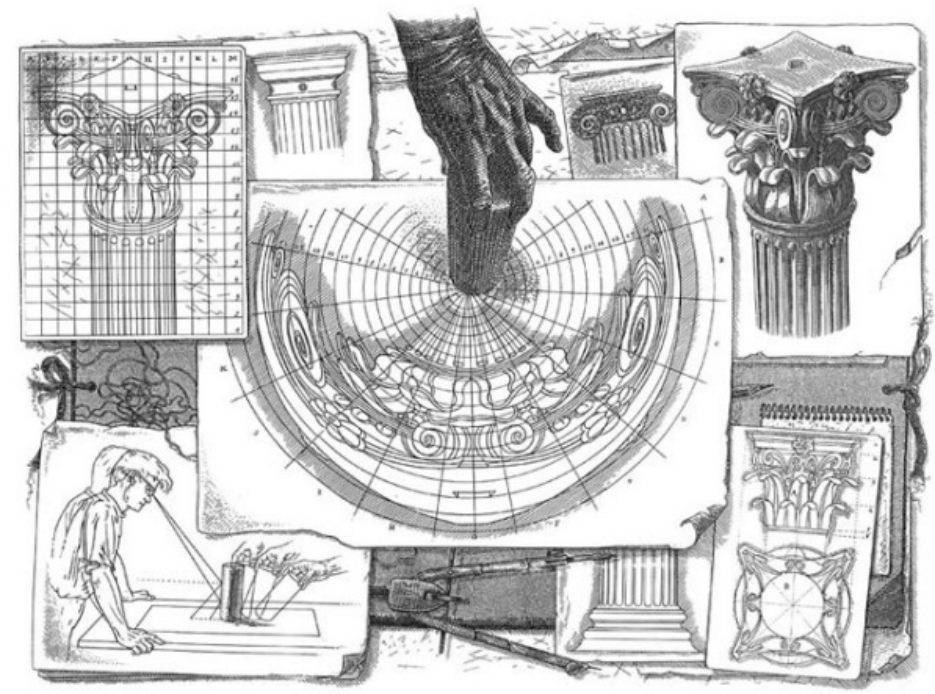

Figura 1: Etapas da construção de uma das principais obras de István Orosz. Fonte [3]

Além da arte, existem vários elementos envolvidos na construção de uma figura anamórfica que são estudados no desenvolvimento de assuntos matemáticos. Buscando mostrar esta aproximação da matemática com esta arte que trabalha com formas, motivando e incentivando os alunos a se desafiarem com estes conteúdos, observar a anamorfose presente no dia-a-dia e associá-la com os conceitos matemáticos que estão sendo estudados.

Esse trabalho busca apresentar a técnica ao leitor e algumas propostas de trabalhar o assunto com alunos do ensino básico.

As etapas desse trabalho vêm sendo aplicadas em algumas turmas do Colégio Estadual do Campo Professor Aloísio, pelo professor Claudio Iavorski, como parte do Trabalho de Conclusão de Curso (TCC) do programa de mestrado PROFMAT. O intuito é utilizar a arte como ferramenta para aceitação, compreensão e aplicabilidade de assuntos matemáticos, durante algumas aulas em diferentes séries e analisar as contribuições dessa forma de abordagem.

\section{Objetivos}

O principal objetivo desse trabalho é buscar, por meio da interdisciplinaridade, associar a arte (uma disciplina que a maioria dos alunos possui empatia), uma ferramenta que motiva o aluno com o aprendizado matemático.

A ideia central deste trabalho é, apresentar ao leitor a técnica de anamorfose em seus aspectos históricos e artísticos mas, principalmente, em seu aspecto matemático.

Pretende-se também explorar a abrangência desse tema em diversos assuntos matemáticos, assim como nos vários níveis da educação básica.

\section{Justificativa}

É muito comum ver alunos desmotivados em aulas de matemática, em alguns casos por serem incentivados a agirem como máquinas de calcular, repetindo procedimentos apresentados como se fossem perfeitos e inquestionáveis, não dando espaço para que o aluno atue como cidadão pensante capaz de melhorar, construir ou reconstruir processos matemáticos.

Já nas aulas de arte é comum ver o oposto, alunos participantes, com opinião e criatividade, porque mesmo essa disciplina tendo seu lado teórico e científico, assim como a matemática, em muitos momentos ela dá espaço para que o aluno exponha sua opinião e construa seu próprio trabalho desde o início. 
Baseado nisso, se vê no anamorfismo um tema capaz de aproximar a matemática da arte e de outras disciplinas como física e história, trazendo melhorias na aceitação pelo aluno e maior participação na geração de ideias.

Assuntos como familiarização com o plano cartesiano ortogonal e outros sistemas de coordenadas, aplicações de funções do primeiro grau, operações com números complexos e representação de números complexos no plano cartesiano, podem ser abordados fazendo com que o aluno aprenda enquanto cria imagens deformadas anamorficamente.

\section{Metodologia}

O anamorfismo foi apresentado inicialmente aos alunos por meio de algumas obras de István Orosz, artista húngaro que explora bastante o anamorfismo cilíndrico. Nesse primeiro contato dos alunos com o anamorfismo, foi possível avaliar a reação deles de forma geral e além disso, perceber relações que alguns alunos fazem, de forma intuitiva, para reconhecer características das imagens.

A distorção da imagem no caso do cilindro ocorre, através de raios de luz paralelos, quando estes atingem o cilindro e são refletidos como ilustra a Figura 2. Mesmo sem este conhecimento, os alunos buscaram fazer associações e tirar suas próprias conclusões.

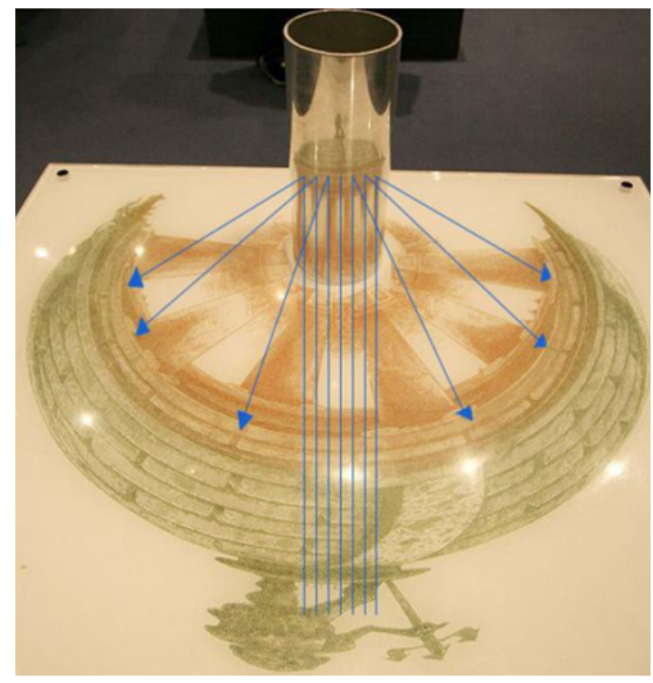

Figura 2: Obra de István Orosz. Fonte:[4]

Essa relação entre a posição dos pontos na imagem deformada e dos pontos na imagem refletida pode ser explicada por vários caminhos matemáticos como o uso de vetores, trigonometria, por exemplo, onde levando em conta a posição do observador e as dimensões do cilindro, é fornecida uma função que leva cada ponto da figura original com coordenadas ortogonais, em um ponto com coordenadas polares, formando assim a figura deformada, Figura 3. 

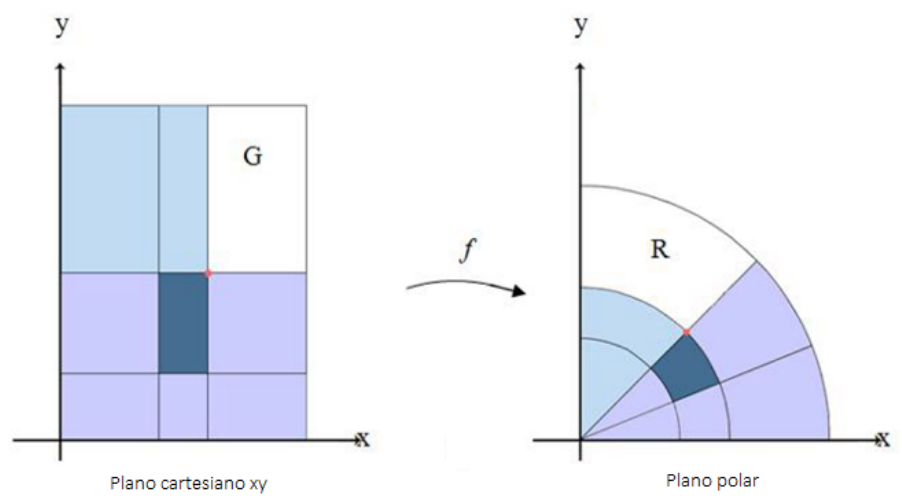

Figura 3: Deformando retângulos. Adaptado da Fonte: [4]

Um aplicativo livre muito útil para criar anamorfismos é o AnamorphMe. Ele pode ser usado tanto pelo professor para levar figuras anamórficas ao aluno, quanto pelo aluno para criar suas próprias imagens deformadas verificando padrões nas deformações. Depois desses padrões serem identificados e generalizados, pode-se fazer com que o aluno crie deformações de figuras geométricas, variando conforme as propriedades do sólido espelhado e do posicionamento do observador, manualmente ou através do Geogebra, outro aplicativo livre.

\section{Resultados}

O trabalho está inicialmente, sendo realizado com alunos do $6^{\circ}$ ano do ensino fundamental e do $2^{\circ}$ ano do médio, na apresentação da técnica artística onde eles tiraram conclusões a respeito do anamorfismo de forma intuitiva e informal para que, posteriormente, com o uso de ferramentas matemáticas, possam fundamentar as suas conclusões e até criar suas próprias figuras anamórficas.

No primeiro contato dos alunos com as obras de István, a reação foi parecida tanto com as crianças do $6^{\circ}$ ano, quanto com os adolescentes do $2^{\circ}$ ano. Inicialmente ficaram impressionados com aquela "mágica" e logo começaram a interagir com a imagem buscando descobrir qual região da figura está associada a parte da imagem que estão vendo.

Busca-se utilizar o tema de várias formas, em diversos assuntos para diferentes níveis de ensino e tanto em matemática, quanto em física, explorando a versatilidade e boa aceitação do aluno ao tema.

Ainda será apresentado o assunto ao $2^{\circ}$ ano na disciplina de física, como aplicação do que foi aprendido em reflexão da luz. Pretende-se imaginar a deformação que o objeto deverá ter, de forma empírica, com o uso de laser e sólidos espelhados. E depois, comprovar essas propriedades matematicamente. Também já foi preparado um questionário com o intuito de verificar a capacidade dos alunos perceberem padrões nas deformações anamórficas e reconhecerem qual região na figura é responsável por cada região na imagem refletida.

Durante as aulas de matemática do $6^{\circ}$ ano, com a intenção de familiarizar o aluno com o plano cartesiano ortogonal, foram feitas figuras no plano quadriculado, relacionando as coordenadas dos pontos com a figura. Indo um pouco além do tradicional, foi sugerido aos alunos que redesenhassem suas figuras em outros planos não ortogonais. Visto que eles tiveram certa facilidade e interesse pelo assunto, foi feito um último desafio. Cada aluno criou uma imagem no plano cartesiano ortogonal e redesenhou no plano polar, onde cada ponto $(x, y)$ é levado em $(\theta, r)$, tal que $\theta=\frac{\pi}{x_{n}} x$ e $r=2 y+3 \operatorname{com} x_{n}$ sendo o valor máximo de $x$.

Na Figura 4, podem ser observados alguns dos trabalhos realizados nesse desafio. 


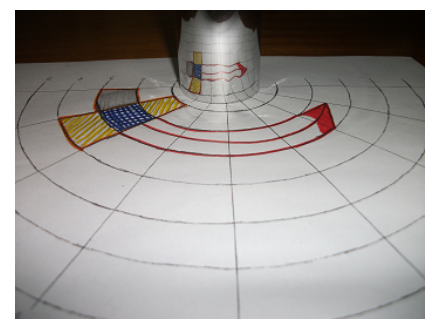

(a) Espada Samurai

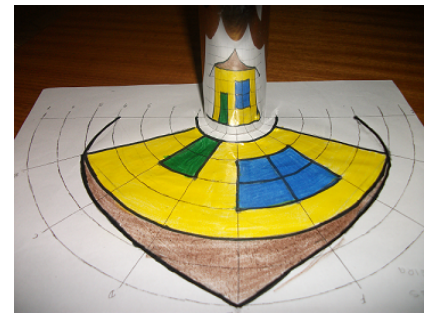

(c) Casa

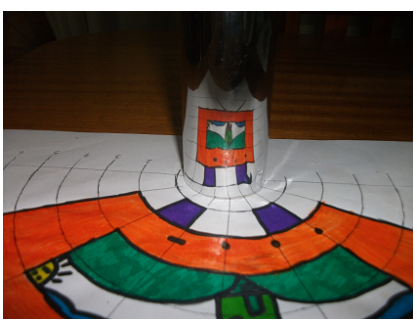

(b) Televisão

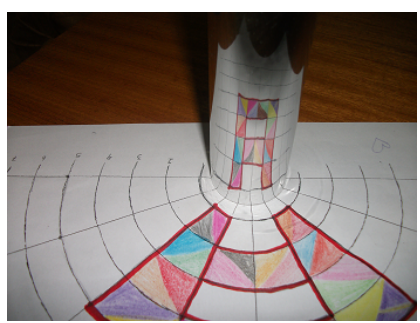

(d) Letra "A"

Figura 4: Anamorfismos cilíndricos construídos por alunos do $6^{\circ}$ ano do Colégio Estadual do Campo Professor Aloísio.

\section{Conclusão}

O anamorfismo, desperta a curiosidade em todos os públicos (desde crianças, até adultos) e por isso é uma ferramenta muito atrativa em todos os níveis de ensino, é motivadora, instigante, desperta a curiosidade do aluno e pode auxilia-lo a visualizar a aplicabilidade e importância do uso de conteúdos de matemática como trigonometria, sistema de coordenadas em outras áreas, como foi observado neste primeiro contato dos alunos com os materiais.

\section{Referências}

[1] LIMA, Rosmari A F, Anamorfose: A matemática na anamorfose, disponível em <http://pt.scribd.com/doc/13140985/A-Matematica-Na-Anamorfose>, acesso em 19 de outubro de 2013.

[2] <http://geometrianamorfose.blogspot.com.br/2008/01/anamorfose-uma-distorcidaprojeco-ou.html>, acesso em 19 de outubro de 2013.

[3] http://obviousmag.org/archives/2010/06/imagen _ magicas_ -_ anamorphoses.html, acesso em 19 de outubro de 2013

[4] SANTOS, Luciano Trajano dos, Anamorfose no ensino da matemática, disponível em <http://dspace.bc.uepb.edu.br:8080/xmlui/bitstream/handle/123456789/486/PDF\%20\%20Luciano\%20Trajano\%20dos\%20Santos\%201.pdf?sequence=1>, acesso em 19 de outubro de 2013 